complete acceptance and application in practice. Architects have subscribed to functionalism for a good many years; and the principle probably has been axiomatic with librarians even longer, even though they may have had difficulty in formulating it and may barely have been conscious of it. Similarly, flexibility has been striven for more or less intelligently in various buildings, including libraries, its advantages presumably having been seen by both designers and occupants. That these ideas should have been played upon repeatedly by speakers at the institute seems encouraging, since their general adoption may depend upon just such exploitation.

The proper division of labor on a building project possibly has not been recognized as generally as have functionalism in plan and flexibility in construction, but its logic is so obvious that the kind of stress placed upon it at the institute should go far to establish it. To be sure, some verbal differences appeared as to just what the librarian should furnish to the architect, in order that the architectural solution of a given problem may proceed and eventuate fruitfully. There was no doubt that he should present the purposes and specific needs of his institution, however, making the requirements so clear and so unmistakable that no interpreter could escape them, be he ever so unlearned in the lore and the operations of libraries. Foresight, planning, hard work, and the willingness to carry his fit responsibility are involved here for the librarian. As the author of one paper pointed out, willingness and capacity to couch his statements in language which nonlibrarians can understand.

The technical papers may prove to vary somewhat in their value. There is much in the treatment of lighting that links up readily with the knowledge and experience of those who operate or work in libraries. It should help in the avoidance of mistakes, and perhaps pave the way for the further education of librarians in a complex and developing field. Perhaps the same can be said about the chapter on the treatment of air, but parts of it may be found difficult going for those who do not have occasion to think daily in terms of dew-point temperature, latent heat, evaporative cooling, and hygroscopic solutions.

As is pointed out in the papers themselves, the discussions are timely because building problems are much in librarians' minds. Before all the buildings now contemplated are under way, it of course is possible that some of the views and data in Library Buildings for Library Service may be outdated and have to be supplemented or superseded. But here is a presently valuable collection of information and viewpoints, essential reading for all who currently face building problems. It represents an important layer in the knowledge and experience regarding the housing of libraries which are being accumulated.-Ernest J. Reece, School of Library Service, Columbia University.

\title{
Graduate Work and Research in the South
}

Graduate Work in the South. By Mary Bynum Pierson. Chapel Hill, University of North Carolina Press, 1947. Published under the sponsorship of the Conference of Deans of Southern Graduate Schools. $265 \mathrm{p}$.

The Graduate School: Research and Publications. Edited by Edgar W. Knight and Agatha Boyd Adams. Chapel Hill, University of North Carolina Press, 1946. (University of North Carolina Sesquicentennial Publications.) 46 ip.

The Graduate School: Dissertations and Theses. Edited by James L. Godfrey, Fletcher M. Green, and W. W. Pierson. Chapel Hill, University of North Carolina
Press, 1947. (University of North Carolina Sesquicentennial Publications.) I84p. Dr. Mary Bynum Pierson's work is the first full-length treatise on graduate work in the South. The professional writings, already voluminous, consist largely of official printed reports, convention proceedings, and articles in professional magazines. Among these contributions are a few, such as the Pierson (W.F.) and Pipkin reports, which deserve the name of studies, as well as books and chapters in books by librarians which appraise the research resources of libraries in the Southern states. The time had come for a comprehensive treatment of the historical setting and problems of graduate work in 
the South which should be based on this widely scattered and episodic material. The author, in attempting such treatment, has revealed the extent and complexity of the subject and has brought together much useful information.

After a brief introduction in which the author outlines the scope of her study, the book deals in two chapters with the history of graduate work in the United States and in the states which comprised the Southern Confederacy. Although Southern efforts were "limited and feeble," the really remarkable thing about graduate instruction in the earliest days was that there was as much of it as there was, and that it was as good as it was. If during these years, no institution was prepared to offer graduate work in the modern sense, at least increased opportunity for higher education was offered through the establishment of graduate programs at Johns Hopkins, Harvard, Princeton, Yale, and $\mathrm{Co}-$ lumbia, and, in a few Southern institutions, especially Virginia and North Carolina. The foundations were laid for "the later development of graduate schools which were to have influence in the entire South." Dr. Pierson notes also that there were important formative influences at work outside of the formal educational program of the colleges. "The economic necessity for scientific agriculture and diversified crops..., the expansion of old and the establishment of new industries, the need for social reforms, and a new interest in universal public education greatly encouraged the development of southern graduate schools for the preparation of research workers, teachers, and leaders for the building of a 'New South."'

Any single analysis of forces affecting the development of graduate work since 1900 is at best only a part of the true picture. Notwithstanding, it can be said with little fear of contradiction, that Dr. Pierson's chapter on "Influences after I900," admirably reflects the forces within and without the universities which have most vitally increased the development of graduate work and research. Dr. Pierson considers these forces under seven heads: ( I) the Southern Association of College and Secondary Schools, (2) the Association of American Universities, (3) the Southern University Conference, (4) Philanthropic Foundations and Private Philanthro- pists, (5) Learned Societies and Journals of Research, (6) Research Institutes, and (7) University Presses. The discussion of these influences is followed by a section on the organization and administration of graduate schools. There is a chapter devoted to graduate work for Negroes. A final chapter discusses what the author believes to be deficiencies in graduate work in the South and examines the opinions of Southern educational leaders as to ways to improvement, and suggests further studies needed to evaluate graduate work in the region. The appendices contain a number of useful tables showing the requirements for advanced degrees in Southern colleges and universities and the doctorates conferred by these institutions. The bibliography at the end of the volume is valuable.

For readers of College and Research Libraries, particular interest is attached to the place of the library in the graduate program. In tightly packed prose, Dr. Pierson shows clearly that Southern college and university libraries made remarkable progress in building collections paralleling the years when the structural organization of most Southern graduate schools was taking place and that librarians and educators have made distinctive contributions in developing manuscript and special collections, interlibrary cooperation, and close ties between the library and graduate school administration. This does not mean that all is for the best in the best of all possible library worlds. Dr. Pierson is very far from being blind to the fact that there are serious deficiencies, and plenty of room for improvement. A study of the statistics with which her book is amply provided will show that the total number of volumes in the major university libraries in the South is only slightly larger than the holdings of any one of the Eastern prestige schools and that there are many libraries within the Southern area which (not necessarily through any fault of their own) can only be described as backward. A carping critic might question her conclusions on the support of private versus state university libraries in the South on the basis of later statistics than those quoted in the Davidson-Kuhlman report. He might wish that certain misleading statements about the location of microphotography laboratories and cooperative library centers in the sources 
quoted had been corrected. He might also wonder whether in realistic terms the interlocking of library and graduate school administrative measures ranks along with the other two distinctive contributions which are mentioned. But what librarian would take issue with an author who is convinced that university libraries, wherever they are welladministered, are doing a great work and require greater support from those responsible for the administration of graduate work! There was a time, not so long ago, when the appearance of a book on graduate work would have burnt the sensitive souls of librarians because no mention was made at all of libraries. But that time is passing. The interest of the public and of educators in libraries is increasing as is evidenced by the Pierson volume and the great series of sesquicentennial publications to which brief reference will now be made.

The University of North Carolina passed its 150 th birthday on Nov. 21, 1939. It was both fitting and significant, therefore, that the university should project as part of its special observance of this anniversary the publication of a series of sesquicentennial publications representing various phases of the history and work of the university.

A brief history of the graduate school, a survey of its resources for research, an account of the university press, and a list of the publications of the faculty make up the volume in the series entitled, The Graduate School: Research and Publications. Dissertations and theses directed by members of the faculty appear in a companion volume under the title, The Graduate School: Dissertations and Theses. The former includes among its contributors such well-known names as Pierson, Coffman, Odum, Couch, Knight, the director and editor-in-chief of the entire series, Louis R. Wilson, as well as four distinguished librarians and professors in special subject fields. If one wishes to get an over-all view of the problems of graduate work and research in a university, with a detailed account of how the University of North Carolina has organized to solve them, the introductory chapter by Dean Pierson will be found most satisfying. Olan V. Cook's account of the resources of the libraries for research complements the more detailed account of book resources edited by Charles Rush and published as a separate volume in the sesquicentennial series under the title Library Resources of the University of North Carolina. No single aspect of the University of North Carolina is more remarkable or deserves higher praise than its record of publication of journals, bulletins, and monographs, which Dr. George R. Coffman discusses in his contribution. A number of these university sponsored journals now bear the imprint of the university press whose work is the subject of a stimulating chapter by the former director of the press, W. T. Couch.

The second great group of material in this volume records the publications of the faculty from the beginnings to the present. This record reflects the extensive interests of the university and the diversified nature of its faculty's scholarship. Some of the writings are highly technical and theoretical in nature. Others are accounts of research work which have a very practical application to industry, government, education, and agriculture. Combined with the list of student dissertations mentioned above, it shows clearly the importance of the university's research work to the state, the region, and the nation.

The reviewer has been asked to call attention briefly to only two of the volumes in this series. He would like to point out to his colleagues that there is a great deal of interest in the whole series to the university librarian. To cite but one contribution, there is an excellent article by Professor Boggs on the building of a folklore collection in Coffman's Studies in Literature and Language. It illustrates beautifully the problem of developing collections which cut across several fields.

The task of editing the series must have been one of immense difficulty, for it required many collaborators. There is considerable repetition which is as understandable as it is annoying to the reader. There is some material that might just as well have been omitted. But aside from these relatively unimportant details, the series as a whole achieves its purpose brilliantly and earns gratitude for the faculty committee on the sesquicentennial celebration, and the University of North Carolina Press.-Guy R. Lyle, Louisiana State University. 